\title{
Evaluation of radiography, ultrasonography and endoscopy for detection of shell lesions in live abalone Haliotis iris (Mollusca: Gastropoda)
}

\author{
Hendrik H. Nollens ${ }^{1, *}$, John C. Schofield ${ }^{2}$, Jonathan A. Keogh ${ }^{1}$, P. Keith Probert ${ }^{1}$ \\ ${ }^{1}$ Department of Marine Science, and ${ }^{2}$ Department of Laboratory Animal Sciences, School of Medical Sciences, \\ University of Otago, PO Box 56, Dunedin, New Zealand
}

\begin{abstract}
Radiography, ultrasonography and endoscopy were examined for their efficacy as nondestructive techniques for the detection of shell lesions in the marine gastropod Haliotis iris Gmelin. X-rays provided $69 \%$ correct diagnoses, with detection being restricted to those lesions which were mineralised. Ultrasound also showed potential to reliably detect lesions (83\% correct diagnoses), but only where the lesions demonstrated a clear 3-dimensional relief. Lesion dimensions were underestimated using ultrasound. Endoscopy, applied to anaesthetised individuals, provided the most accurate method (92\% correct diagnoses) for lesion detection and, although invasive, had no discernible effect on survival of the abalone 8 mo after screening.
\end{abstract}

KEY WORDS: Abalone · Haliotis · Gastropoda $\cdot$ Shell lesion · Detection · Radiography · Ultrasonography $\cdot$ Endoscopy

Resale or republication not permitted without written consent of the publisher

\section{INTRODUCTION}

A range of shell-invading organisms associated with live abalone has been reported in the literature (Kojima \& Imajima 1982, Clavier 1992, Thomas \& Day 1995), although in most cases the effects of such organisms on their host remains to be ascertained. The 3 New Zealand species of abalone often exhibit irregularities on the interior shell surface, and there is evidence that these may be associated with a fungus that has invaded the shell (Friedman et al. 1997, Grindley et al. 1998). These so-called shell lesions usually consist of a brown, soft jelly-like substance; occasionally a mineralised, nacreous layer partially envelops the soft jelly-like substance (Fig.1). Lesions are always evident at the apical region of the shell and, in larger lesions, extend from the apex to the attachment site of the adductor muscle.

*E-mail: hendrik.nollens@advalvas.be
Grindley et al. (1998) reported shells in which the lesion had invaded the adductor muscle attachment site, potentially resulting in the abalone losing its shell. Aquaculturists also reported this condition to cause fatalities to abalone kept in captivity. In addition, it has been suggested that wild populations with affected individuals may experience either reduced growth and/or elevated mortality (Grindley et al. 1998). Friedman et al. (1997) isolated a fungal pathogen, associated with all of the affected shells of Haliotis iris and H. australis. Furthermore, a significant relationship could be established between the number of circulating haemocytes and the degree of shell mycosis in $H$. australis. This was thought to represent a sign of stress or response to the shell disease (Friedman et al. 1997).

Determining the effect of shell lesions on growth, reproduction and survival of affected abalone and clarifying the role of the fungus and/or the epibionts in the pathogenesis of the lesions are important areas for further research. However, the location of the lesions on the inside of the shell compromises their non-destruc- 


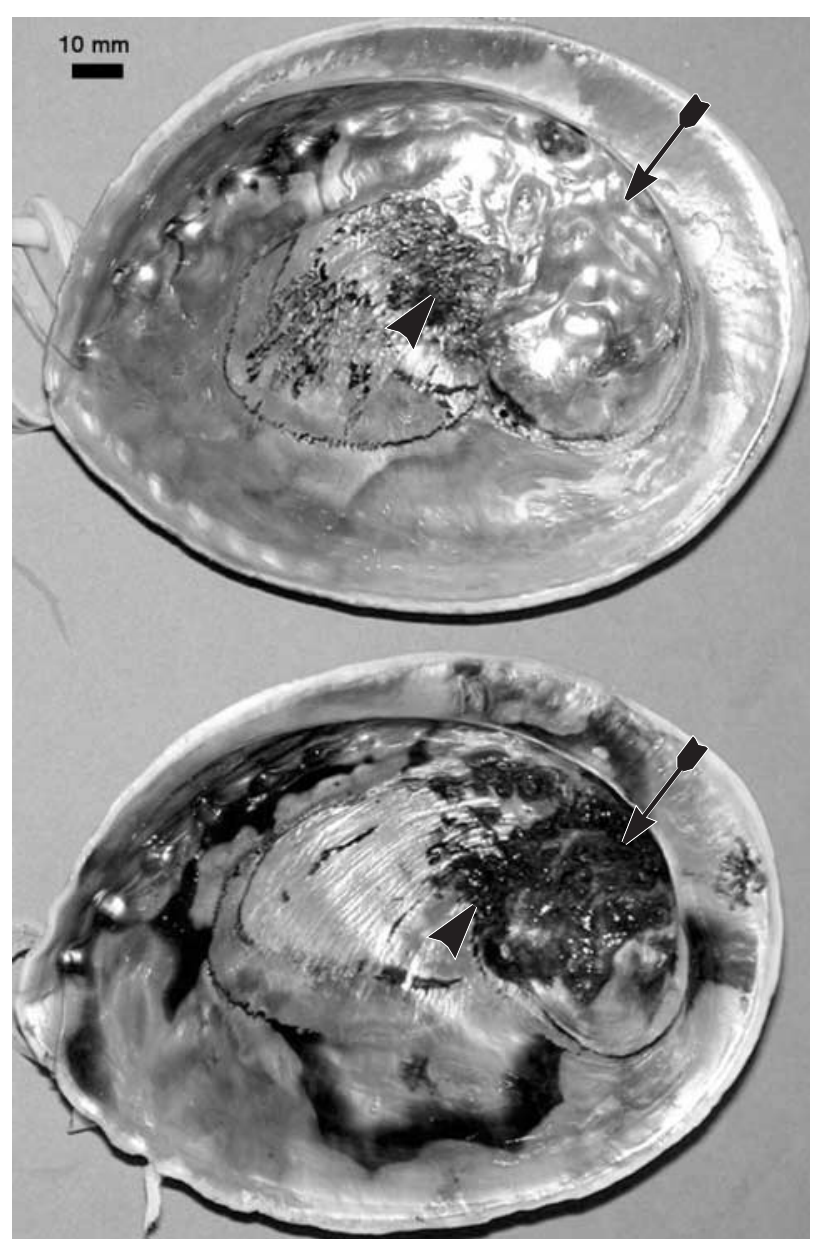

Fig. 1. Haliotis iris. Lesions (arrows) of a more mineralised nature (top specimen) are more accurately diagnosed using radiography than lesions of a soft jelly-like consistency (bottom specimen). Affected areas of the adductor muscle attachment sites are indicated by arrowheads

tive detection and thus hampers experimental investigation. Schofield et al. (2001) recently reported that diagnostic radiology accurately detected the presence of lesions in Haliotis iris in $96 \%$ of the cases examined, after lesions exceeded $6.2 \times 7.1 \mathrm{~mm}$ in size. However, this method is cumbersome, underlies strict health and safety requirements, and is not readily available, prompting our consideration of other non-destructive methods for reliable determination of the presence of lesions. Ultrasonography has previously been used as a non-invasive tool for monitoring internal and external biomechanical and physiological events in marine molluscs and for sexing and assessing ovarian maturation of teleost fish (Davenport 1993, Haefner et al. 1996, Martin-Robichaud \& Rommens 2001). Similarly, videoendoscopy has been applied to molluscs to examine suspension-feeding mechanisms (Ward et al. 1993) and for the sex assessment of fishes (Moccia et al. 1984,
Ortenburger et al. 1996). There are, however, no records of either technique having been applied in molluscan pathology.

We describe herein the methods used in applying ultrasonography and endoscopy for detection of shell lesions in the marine gastropod Haliotis iris. The results of 3 investigations during which radiography, ultrasonography and endoscopy were applied to lesionbearing and non-lesion bearing $H$. iris are given and compared with those obtained directly via dissection.

\section{MATERIALS AND METHODS}

Trial 1: Comparison of radiography and ultrasonography. On 12 May 2000, 83 abalone were collected using SCUBA from Jack's Bay $\left(46^{\circ} 33^{\prime} \mathrm{S}, 169^{\circ} 36^{\prime} \mathrm{E}\right)$, Otago, southeastern New Zealand. The abalone were transported to the Portobello Marine Laboratory, near Dunedin, where they were uniquely marked with a random 4-digit number, using $15 \mathrm{~mm}$ plastic tags fixed to the shell with an acrylic adhesive. The tags were positioned on the anterior of the shell, on the opposite side to the respiratory pores. The abalone were left to acclimatize for $1 \mathrm{wk}$ in $1400 \times 760 \times 225 \mathrm{~mm}$ tanks; all but 1 tank contained 21 individuals. Each tank was individually supplied with flow-through sand-filtered seawater at approximately $121 \mathrm{~min}^{-1}$. The abalone were supplied with the macroalga Macrocystis pyrifera Bory, 1826, ad libitum, which was replenished twice weekly.

Ultrasound screening was achieved using 3.5, 5 and $7 \mathrm{MHz}$ transducer probes connected to a BCF Technology Oviscan 4 apparatus. Immediate images were obtained on screen and permanent images were captured using a Sony Video Graphic printer UP-890CE. Lesion dimensions were measured on-screen to the nearest $1 \mathrm{~mm}$, using the machine's caliper function, and recorded. Abalone were screened on the third day after collection. During screening, they were held submerged in running seawater, while the probe, although submerged, was not brought into direct contact with them.

The following day, all abalone were X-rayed using a Siemens diagnostic radiology unit, connected to an image-intensifier fluoroscopy unit. The equipment, technique and exposure settings have been described by Schofield et al. (2001): focal distance $100 \mathrm{~cm}, 50 \mathrm{kV}$, $20 \mathrm{~mA}$ seconds.

All abalone were then dissected, the presence or absence of lesions was noted and shell length and lesion dimensions were recorded to the nearest $1 \mathrm{~mm}$ using calipers.

Trial 2: Endoscopy. On 24 October 2000, a further 123 abalone were collected from Jack's Bay and trans- 
ported to the Portobello Marine Laboratory, where they were uniquely tagged and measured as above. The abalone were divided into 3 groups based on shell length (small, medium and large; Table 1). Those in the small and large groups were subjected to endoscopy only, while the medium-sized individuals were randomly allocated to 1 of 4 treatments: endoscopy (Treatment 1), ultrasonography (Treatment 2), endoscopy and subsequent ultrasonography (Treatment 3) and a control group (Treatment 4), as indicated in Table 1.

On the second day after collection, the abalone were anaesthetised using sodium pentobarbitone in $1 \mathrm{ml} \mathrm{l}^{-1}$ seawater at $23^{\circ} \mathrm{C}$ (Aquilina \& Roberts 2000) prior to endoscopic examination. Groups of 5 individuals were simultaneously submerged in $5 \mathrm{l}$ of anaesthetic solution. For each group, a new solution was prepared. After full muscle relaxation was achieved, determined as the lack of response to tactile stimuli (20 to $35 \mathrm{~min}$ ), a rigid Karl Storz Arthroscope connected to a Karl Storz Endoscope Cold Light Fountain 482 was introduced via the gill chamber, inserted dorsally to the pericardium and advanced into the apex of the shell (Fig. 2). The presence of lesions was noted. The position of the probe, and thus the anterior margin of the lesion, could be determined as the light source was sufficiently strong to be seen as a light spot on the exterior of the shell. Ultrasonography was performed on the third day after collection, following the procedure described above.

After screening, the different treatment groups were kept in separate tanks for a minimum of $19 \mathrm{~d}$ to monitor aberrant behaviour and mortality due to handling and treatment procedures. The $1400 \times 760 \times 225 \mathrm{~mm}$ tanks received flow-through sand-filtered seawater at approximately $121 \mathrm{~min}^{-1}$ and the abalone were fed ad libitum with Macrocystis pyrifera. The abalone were

Table 1. Haliotis iris. Trial 2: Total number (n) in the different size classes (small, medium and large) and treatments (endoscopy, ultrasonography, endoscopy + ultrasonography, control) together with the number and percentage (in parentheses) of mortalities in each size class following treatment

\begin{tabular}{|lcccc|}
\hline Size class & Endoscopy & $\begin{array}{c}\text { Ultra- } \\
\text { sonography }\end{array}$ & $\begin{array}{c}\text { Endoscopy }+ \\
\text { ultrasonography }\end{array}$ & Control \\
\hline $\begin{array}{l}\text { Small }(<110 \mathrm{~mm}) \\
\mathrm{n}\end{array}$ & 23 & 0 & 0 & 0 \\
$\quad$ Mortality & $1(4 \%)$ & & & \\
$\begin{array}{l}\text { Medium }(110-120 \mathrm{~mm}) \\
\mathrm{n}\end{array}$ & 24 & 19 & 18 & 16 \\
$\mathrm{M}$ Mortality & $10(42 \%)$ & $1(5 \%)$ & $1(6 \%)$ & $1(6 \%)$ \\
$\begin{array}{l}\text { Large }(>120 \mathrm{~mm}) \\
\mathrm{n}\end{array}$ & 24 & 0 & 0 & 0 \\
Mortality & $1(4 \%)$ & & & \\
\hline
\end{tabular}
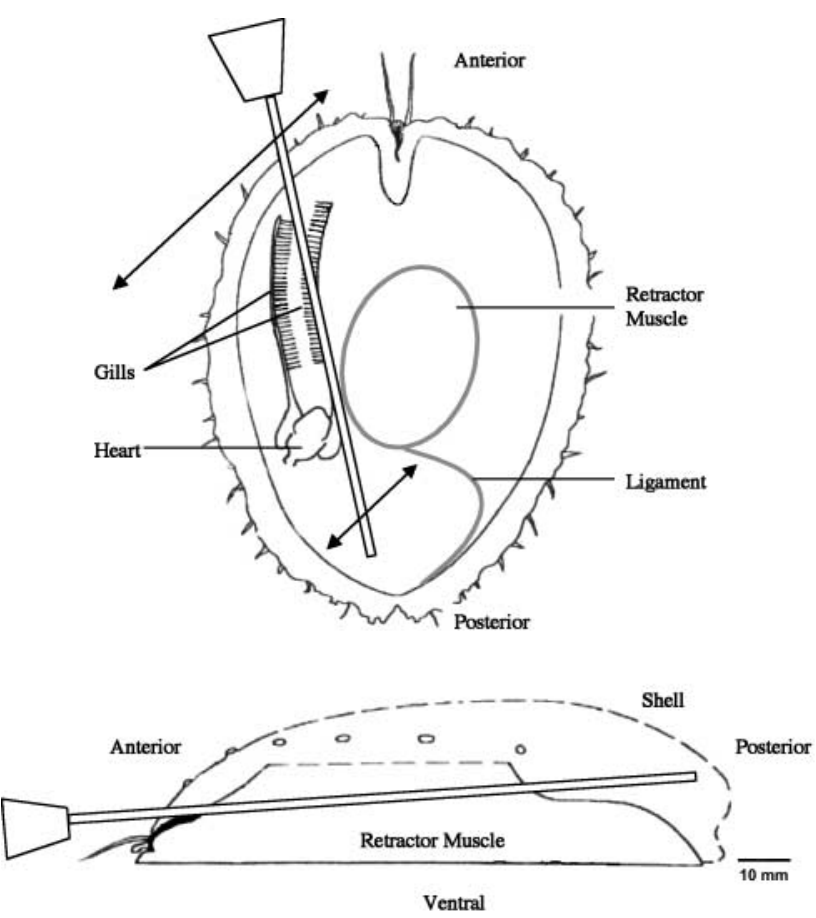

Fig. 2. Schematic diagramme of overhead view (top graph) and side view (bottom graph) of the insertion and sideways manoeuvrability (arrows) of the endoscope in Haliotis iris

inspected daily and dead individuals removed for immediate dissection. At the end of this period, all remaining live abalone allocated to the endoscopyonly treatment were dissected from their shell, using a commercial abalone iron, and examined for the presence of lesions.

Trial 3: Endoscopy-related mortality. A third trial was conducted to further explore the potential for endoscopy-related mortality. On 3 December 2000, 182 abalone were collected from Jack's Bay, transported, tagged, anaesthetised and subjected to endoscopy as above. After screening, the abalone were returned to tanks with flow-through sand-filtered seawater and monitored daily for 8 mo. Dead individuals were removed and immediately dissected.

Lesion mineralogy. Two lesionbearing shells (1 undetected and 1 detected by radiography) were sampled to determine their chemical composition. One sample (DL-1) was scraped from inside the detected lesion and a second sample (DL-2), from the same lesion, was taken from the outer crust. A third sample (UDL) was scraped from the undetected lesion. 
All samples were ground to a fine powder with an agate mortar and pestle. Halite was used as an internal standard. Distilled water was added to form a slurry and the resulting material was smeared on a glass slide. After drying at approximately $80^{\circ} \mathrm{C}$ until a constant dry weight was reached, the randomly-oriented samples were placed in a Philips X-Ray diffractometer, and run from 25 to $32^{\circ} \mathrm{C}$ at 50 steps per degree, 2 s per step, as described in Smith et al. (1998).

\section{RESULTS}

\section{Trial 1: Comparison of radiography and ultrasonography}

X-ray provided correct diagnoses in a total of 57 of the cases (69\%; Table 2). Two animals were incorrectly diagnosed as affected (false positive) and 24 of the lesions were undiagnosed (30\%; Table 2). The surface area of 2 of the undiagnosed lesions measured less than $3 \times 3 \mathrm{~mm}$; a further 2 were from individuals that were heavily fouled with tubeworms and barnacles. Undiagnosed lesions $(\mathrm{n}=24)$ measured $19.1 \pm 9.7 \times$ $20.7 \pm 12.0 \mathrm{~mm}$ across and were $2.8 \pm 1.5 \mathrm{~mm}$ high . This was not significantly different $(p>0.05)$ from the mean lesion dimensions of detected lesions $(\mathrm{n}=8$, $26.1 \pm 9.5 \times 31.8 \pm 19.8 \mathrm{~mm}$ across and $3.5 \pm 2.5 \mathrm{~mm}$ high). The smallest lesion detected by radiography was $9 \times 5 \mathrm{~mm}$ across and $1 \mathrm{~mm}$ high.

The $5 \mathrm{MHz}$ ultrasound transducer probe proved to be the most effective method for detecting lesions when coupled with a BCF Technology Oviscan 4 apparatus (Fig. 3). A $7 \mathrm{MHz}$ transducer probe provided images of higher resolution, but lacked penetration capacity in larger abalone. In contrast, insertion of a $3.5 \mathrm{MHz}$ probe increased the penetration capacity, but reduced the capacity for detecting smaller lesions, due to the lower resolution of the image of the inner shell surface.

Ultrasound yielded 69 correct diagnoses (83\%; see Table 2). The 1 false positive diagnosis was attributed to the abalone having a pronounced bump on the

Table 2. Haliotis iris. Trial 1: Number and percentage correctly and incorrectly diagnosed by X-ray imaging and ultrasonography compared to results for dissection. No. diagnosed per treatment $=83$

\begin{tabular}{|lccc|}
\hline Diagnosis & X-ray & Ultrasound & Dissection \\
\hline $\begin{array}{l}\text { Correctly diagnosed as: } \\
\text { 'unaffected' }\end{array}$ & $49(59 \%)$ & $50(60 \%)$ & $51(61 \%)$ \\
$\quad$ 'affected' & $8(10 \%)$ & $19(23 \%)$ & $32(39 \%)$ \\
Falsely diagnosed as: & & & \\
$\quad$ 'affected' & $2(2 \%)$ & $1(1 \%)$ & 0 \\
'unaffected' & $24(30 \%)$ & $13(16 \%)$ & 0 \\
\hline
\end{tabular}
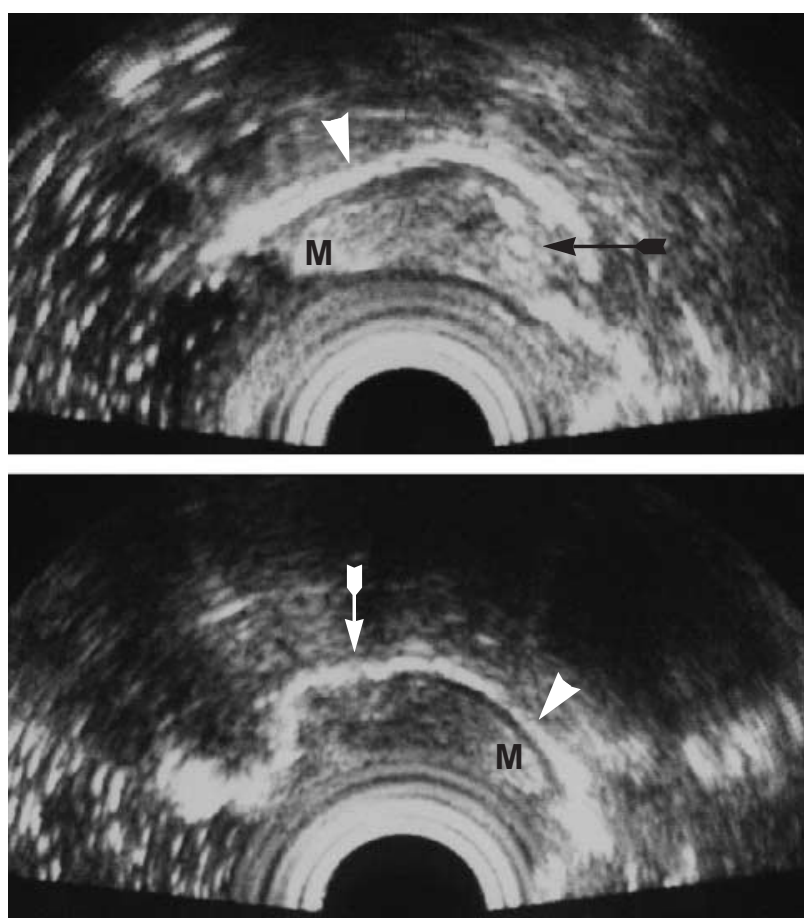

Fig. 3. Haliotis iris. Ultrasound image of unaffected (top) and affected (bottom) specimens. Shell (arrowheads), heart (black arrow), foot (M) and lesion (white arrow) are indicated

inside of the shell. Among the 13 false negative diagnoses $(16 \%)$, 3 had lesions measuring under $3 \times 3 \mathrm{~mm}$. Mean lesion width, length and height of the remaining 10 undiagnosed abalone were $19.6 \pm 5.5,24.6 \pm 9.3$ and $1.5 \pm 0.8 \mathrm{~mm}$ respectively, which was not significantly different $(p>0.5)$ from the mean dimensions of the lesions correctly diagnosed using ultrasonography ( $\mathrm{n}=19,24.4 \pm 9.5 \times 26.2 \pm 15.8 \mathrm{~mm}$ across and $3.9 \pm 1.6$ $\mathrm{mm}$ high). The least prominent lesion correctly diagnosed was only $2 \mathrm{~mm}$ high, while the most prominent undiagnosed lesion was $3 \mathrm{~mm}$ high. Ultrasonography tended to underestimate lesion surface area (Fig. 4), except in 4 cases where lesion area was overestimated, with 2 adjacent but separate lesions being interpreted as 1 large lesion.

The abalone ranged in shell length from 101 to $153 \mathrm{~mm}$, with the sample population skewed towards the lower end of the size range (Table 3). Lesions ( $\mathrm{n}=32$ ) measured $20.9 \pm 10.0 \times 23.5 \pm$ $14.8 \mathrm{~mm}$ across and were $3.0 \pm 1.8 \mathrm{~mm}$ high. Some lesions $(n=29)$ appeared as brown, gelatinous non-mineralised tissue (Fig. 1); of these lesions, 6 (21\%) were correctly diagnosed by radiography. Of the 3 highly mineralised lesions, 2 were correctly diagnosed using X-ray. Lesions undiagnosed by 


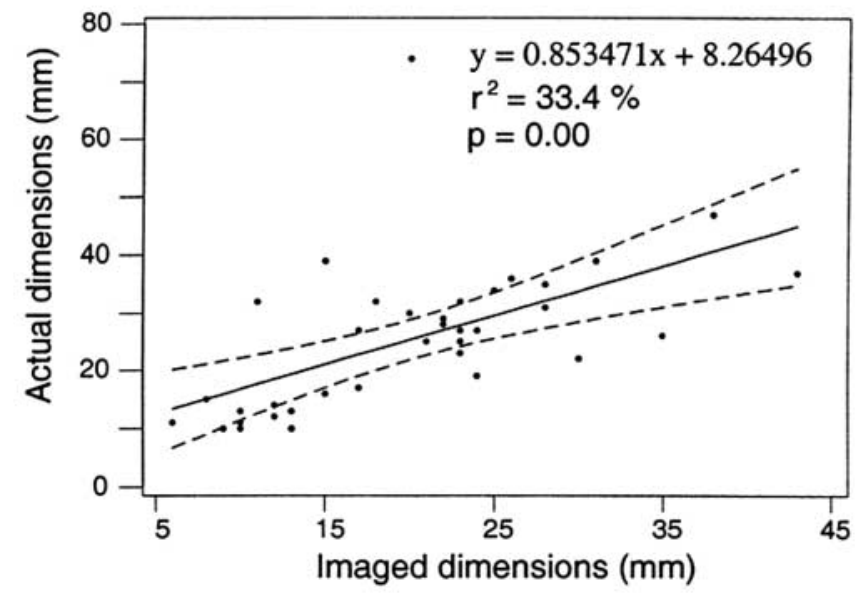

Fig. 4. Haliotis iris. Regression (solid line) and 95\% confidence limits (broken lines) between lesion dimensions determined by ultrasound and actual dimensions determined by dissection

X-ray were found in small and large individuals, whereas lesions undiagnosed by ultrasound tended to be in the smaller size classes (Table 3). Lesion surface area ranged between $3 \times 2 \mathrm{~mm}$ and $37 \times 74 \mathrm{~mm}$. Shell length and lesion surface area were not significantly correlated $\left(\mathrm{r}^{2}=0.11, \mathrm{p}>0.05\right)$.

\section{Trial 2: Endoscopy}

Individuals varied in their susceptibility to anaesthesia. Some required $20 \mathrm{~min}$ immersion in the anaesthetic to obtain full muscle relaxation, while others needed up to $35 \mathrm{~min}$.

Endoscopic examination provided correct diagnoses in 65 of the abalone examined (92\%; Table 4). One false positive diagnosis was associated with a darkbrown stain on the inside of the shell. The 5 false neg-

Table 3. Haliotis iris. Trial 1: Lesion occurrence and number of abalone incorrectly diagnosed by X-ray imaging and ultrasonography, as a function of shell length. $\mathrm{n}=$ number of abalone sampled (total $\mathrm{n}=83$ )

\begin{tabular}{|lrrrrr|}
\hline \multirow{2}{*}{$\begin{array}{l}\text { Shell length } \\
(\mathrm{mm})\end{array}$} & $\mathrm{n}$ & \multicolumn{2}{c}{$\begin{array}{c}\text { Status } \\
\text { Unaffected }\end{array}$} & Affected & \multicolumn{2}{c|}{$\begin{array}{c}\text { False diagnoses } \\
\text { X-ray }\end{array}$} \\
& & & & $\begin{array}{c}\text { Ultrasono- } \\
\text { graphy }\end{array}$ \\
\hline $100-104$ & 11 & $4(36 \%)$ & $7(64 \%)$ & $6(55 \%)$ & $3(27 \%)$ \\
$105-109$ & 15 & $10(67 \%)$ & $5(33 \%)$ & $4(27 \%)$ & $3(20 \%)$ \\
$110-114$ & 26 & $15(58 \%)$ & $11(42 \%)$ & $9(35 \%)$ & $6(23 \%)$ \\
$115-119$ & 5 & $3(60 \%)$ & $2(40 \%)$ & $1(20 \%)$ & $1(20 \%)$ \\
$120-124$ & 2 & 0 & $2(100 \%)$ & $2(100 \%)$ & $1(50 \%)$ \\
$125-129$ & 3 & $2(66 \%)$ & $1(33 \%)$ & 0 & 0 \\
$130-134$ & 4 & $3(75 \%)$ & $1(25 \%)$ & $1(25 \%)$ & 0 \\
$135-139$ & 7 & $6(86 \%)$ & $1(14 \%)$ & $1(14 \%)$ & 0 \\
$140-144$ & 6 & $5(83 \%)$ & $1(17 \%)$ & $1(17 \%)$ & 0 \\
$145-149$ & 1 & $1(100 \%)$ & 0 & 0 & 0 \\
$150-155$ & 3 & $2(67 \%)$ & $1(33 \%)$ & $1(33 \%)$ & 0 \\
\hline
\end{tabular}

Table 4. Haliotis iris. Trial 2: Number and percentage correctly and incorrectly diagnosed using endoscopy. No. diagnosed per treatment $=71$

\begin{tabular}{|c|c|c|}
\hline \multirow[t]{2}{*}{ Diagnosis } & \multicolumn{2}{|c|}{ No. and (\%) diagnosed } \\
\hline & Endoscopy & Dissection \\
\hline \multicolumn{3}{|c|}{ Correctly diagnosed as: } \\
\hline 'unaffected' & $42(60 \%)$ & $47(66 \%)$ \\
\hline 'affected' & $23(32 \%)$ & $24(34 \%)$ \\
\hline \multicolumn{3}{|c|}{ Falsely diagnosed as: } \\
\hline 'affected' & $1(1 \%)$ & 0 \\
\hline 'unaffected' & $5(7 \%)$ & 0 \\
\hline
\end{tabular}

ative diagnoses occurred where lesions were either located in the inner tip of the shell, making them inaccessible for the rigid arthroscope $(n=4)$, or were due to minimal lesion relief $(<1 \mathrm{~mm})$. Because of the high variation of lesion morphology and the comparatively small dimensions of the endoscope lens ( $3 \mathrm{~mm}$ diameter), no attempts were made to estimate lesion dimensions using endoscopy.

In the $19 \mathrm{~d}$ following the experiment, 1 individual died in each of the ultrasound, the endoscopy + ultrasound, the control treatments and the large and small group subjected to endoscopy. In contrast, $10(42 \%)$ of the abalone in the medium-sized group died within $24 \mathrm{~h}$ of examination (Table 1). These 10 individuals belonged to 3 consecutively screened groups which behaved differently (i.e. cramping up instead of relaxing) during induction of anaesthesia. Macroscopic examination of the dead individuals revealed no gross soft-tissue lesions.

Sampled abalone ranged in shell length between 65 and $155 \mathrm{~mm}$, with the affected abalone ranging between 104 and $155 \mathrm{~mm}$ (Table 5). Insufficient lesions were diagnosed $(n=6)$ to conclude that the accuracy of the endoscopic method varied among the different size-groups (Table 5). No significant relationship could be established between shell length and lesion dimensions $\left(\mathrm{r}^{2}=\right.$ $0.09, \mathrm{p}>0.05$ ).

\section{Trial 3: Endoscopy-related mortality}

The 182 abalone used for this experiment included 82 medium-sized individuals $(110$ to $120 \mathrm{~mm})$. During $8 \mathrm{mo}$ of postprocedure monitoring, a total of $6(3 \%)$ individuals died; 4 deaths (of which only 1 involved a medium-sized individual) resulted directly from the abalone escaping from their tanks. Dissection of the remaining 2 dead individuals revealed no gross soft tissue injury. No mortalities were recorded in the first $24 \mathrm{~d}$ after endoscopy. 


\section{Mineralogy lesion}

Sample DL-1 consisted of powdery pale brown material filling the protruding part of the lesion. Sample DL2 consisted of hard black material from the outer crust of the same lesion. Although Sample UDL was black and hard, no powdery material was found inside this smaller lesion. All 3 samples of the shell lesions were composed entirely of aragonite.

\section{DISCUSSION}

Schofield et al. (2001) developed a radiological technique to detect shell irregularities in abalone. They obtained $96 \%$ correct diagnoses $(n=47)$ and the minimum detectable lesion size was $6.2 \times 7.1 \mathrm{~mm}$. However, the present study indicates a lower accuracy for the X-ray method (only $69 \%$ correct diagnoses, $\mathrm{n}=71$ ). Exposure factors of $\mathrm{kV}, \mathrm{mA}$ and focal film distance were varied in an attempt to increase the accuracy of the X-ray method, but no noteworthy differences were observed in the quality of the image. X-ray yielded a low proportion of falsely positive individuals $(2 \%)$ and underestimated the presence of lesions (Table 2). The surface area of undiagnosed lesions varied greatly ( $\mathrm{n}=$ $24 ; 19.1 \pm 9.7 \times 20.7 \pm 12.0 \mathrm{~mm}$ ) and did not differ significantly $(p>0.05)$ from the mean lesion surface area of the correctly diagnosed lesions $(n=8 ; 26.1 \pm 9.5 \times$ $31.8 \pm 19.8 \mathrm{~mm}$ ). Thus, lesion surface area is not important in the accuracy of the radiography. Schofield et al. (2001) observed the lesions as radio-dense tissue. The predominant lesion type observed in the present study was soft, brown, gelatinous, amorphous tissue, which appeared on X-rays as dark, radio-opaque areas. The lesions described by Grindley et al. (1998) and

Table 5. Haliotis iris. Trial 2: Lesion occurrence and number of abalone incorrectly diagnosed using endoscopy, as a function of shell length. No data available for abalone between 75-89 and 95-99 mm. $\mathrm{n}=$ number of abalone

\begin{tabular}{|lcccc|}
\hline \multirow{2}{*}{$\begin{array}{l}\text { Shell length } \\
(\mathrm{mm})\end{array}$} & $\mathrm{n}$ & \multicolumn{2}{c|}{ Status } & \multirow{2}{*}{ False } \\
& & Unaffected & Affected & diagnoses \\
\hline $65-69$ & 1 & $1(100 \%)$ & 0 & 0 \\
$70-74$ & 1 & $1(100 \%)$ & 0 & 0 \\
$90-94$ & 1 & $1(100 \%)$ & 0 & 0 \\
$100-104$ & 1 & 0 & $1(100 \%)$ & 0 \\
$105-109$ & 5 & $2(4 \%)$ & $3(60 \%)$ & 0 \\
$110-114$ & 15 & $4(27 \%)$ & $11(73 \%)$ & $3(20 \%)$ \\
$115-119$ & 15 & $7(47 \%)$ & $8(53 \%)$ & $1(7 \%)$ \\
$120-124$ & 7 & $3(43 \%)$ & $4(57 \%)$ & 0 \\
$125-129$ & 6 & $3(50 \%)$ & $3(50 \%)$ & $2(33 \%)$ \\
$130-134$ & 2 & 0 & $2(100 \%)$ & 0 \\
$135-139$ & 8 & $2(25 \%)$ & $6(75 \%)$ & 0 \\
$140-144$ & 4 & 0 & $4(100 \%)$ & 0 \\
\hline
\end{tabular}

Schofield et al. (2001) were characterised by an increase in shell mineral deposition and a thickened inner shell (see present Fig.1). Gelatinous, amorphous tissue is expected to be radio-opaque, whereas shell mineral deposits appear as radio-dense, white lesions. This agrees with our findings which suggest higher accuracy for the detection of lesions of pronounced mineralised nature (66\%) compared to lesions of a gelatinous nature $(21 \%)$. X-ray diffraction analysis of the 2 lesion types ascertained that the mineralogy of the gelatinous and the more mineralised lesion type are not different. Both lesions consisted entirely of aragonite, which typically makes up the inner layer of the shell of Haliotis spp. (Vermeij 1993). This suggests that it is not the chemical characteristics of the lesion substance, but rather different radiographic properties, such as lesion substance density and thickness, which caused radiography not to detect lesions accurately. Unfortunately, the low number of affected individuals correctly diagnosed by radiography $(n=8)$ did not allow us to assess any correlation between lesion height (as a measure of lesion thickness) and diagnostic accuracy of the radiographic technique.

For ultrasonographic diagnosis, the probe cannot be brought into direct contact with the moving abalone, since a stable image is required for accurate diagnosis and measurement. Hence, both the abalone and the transducer probe were held submerged in a seawater basin with the seawater acting as the medium for conduction of ultrasound waves between probe and abalone. Ultrasonography was more accurate than radiography (83 and 69\% correct diagnoses, respectively; Table 2). The ultrasonographic technique yielded a low percentage of false positive diagnoses $(1 \%)$, but underestimated the presence of lesions. Again, the surface area of undiagnosed lesions varied $(19.6 \pm 5.5 \times 24.6 \pm 9.3 \mathrm{~mm})$ and there was overlap with the mean lesion surface area of the correctly diagnosed lesions $(24.4 \pm 9.5 \times 26.2 \pm 15.8 \mathrm{~mm})$. Similar to radiography, lesion surface area was not important to the accuracy and detection limit of the ultrasonographic technique. In contrast, the need for lesions to have 3dimensional relief appeared more critical to lesion detection (mean lesion height of correctly diagnosed lesions $=3.9 \pm 1.6 \mathrm{~mm}$; mean height of undiagnosed lesions $=1.5 \pm 0.8 \mathrm{~mm}$ ). Also, lesion dimensions using ultrasound were usually underestimated (Fig. 4), since the peripheral, less prominent parts of lesions were not evident on screen.

In un-anaesthetised abalone, the rigid endoscope could not be inserted as the contracted foot and epipodium are inflexible. To overcome this, several anaesthetics (e.g. benzocaine, MS 222, magnesium sulphate, 2-phenoxyethanol and pentobarbitone), all of which have been identified as suitable for abalone 
(Hahn 1989, Tong et al. 1992, White et al. 1996, Aquilina \& Roberts 2000) were evaluated. Unlike the other anaesthetics, pentobarbitone results in a malleable foot and epipodium and thus was utilised herein. All abalone sampled herein required between 20 and 35 min immersion in the anaesthetic solution to achieve full muscle relaxation, whereas Aquilina \& Roberts (2000) regarded just 15 min immersion as sufficient for their purposes. While increased immersion times can not be discounted as contributory factors to the deaths observed in Trial 2 (Table 1), it is clear that in Trial 3 only 2 of the 182 abalone $(1 \%)$ died postprocedure. This level of mortality is low and, moreover, could not be solely ascribed to the procedure, because the mortalities did not occur until at least $24 \mathrm{~d}$ after the procedure. Thus, both the anaesthesia and the endoscope can be applied as diagnostic methods for shell lesions without concern for increased levels of mortality in Haliotis iris.

Endoscopy yielded the greatest number of correct diagnoses (92\% correct diagnoses for $\mathrm{n}=71)$ and holds many advantages over the other methods evaluated here (Table 6). Endoscopy yielded the lowest percentage of both false positive $(1 \%)$ and false negative $(7 \%)$ diagnoses. Of the 5 undiagnosed lesions, 4 occurred in the tip of the shell, which was considered inaccessible to the rigid arthroscope. A manoeuvrable endoscope (e.g. bronchoscope) may reduce the number of undiagnosed lesions in future applications; this device would be especially suitable for smaller individuals.

The abalone dissected in this study ranged between 65 and $155 \mathrm{~mm}$ in shell length $(\mathrm{n}=154$; Tables 3 \& 5). The smallest and largest affected individuals measured 101 and $155 \mathrm{~mm}$ respectively. This is only slightly different than the known range of affected

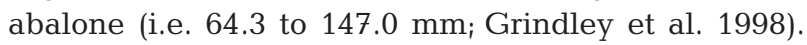
The sample population $(\mathrm{n}=71)$ utilised for endoscopy (Table 5) comprised individuals representing a wider range of sizes than the sample population utilised for radiography (see Table 3). Nevertheless, there was no correlation between shell length and lesion surface $\left(r^{2}=0.09, p=0.072\right)$. This agrees with data of Grindley et al., who reported that a large size range of both Haliotis iris and $H$. australis exhibited advanced lesions. In addition, although a significant trend of increasing prevalence of lesions with increasing shell length has been reported in $H$. australis (Grindley et al. 1998), this trend was not present in the $H$. iris sampled for their study. In our study we observed a tendency toward higher lesion prevalence in larger $H$. iris (Table 5). However, this could not be tested, due to the shortage of individuals smaller than $100 \mathrm{~mm}$.

The evaluation of X-ray, ultrasound and endoscopy as non-destructive methods for the reliable detection of shell lesions in Haliotis iris reported here has clearly
Table 6. Haliotis iris. Comparison of radiography, ultrasonography and endoscopy as diagnostic tools for detecting shell lesions in abalone. Relative advantages (+) and disadvantages (-)

\begin{tabular}{|lccc|}
\hline Characteristic & $\begin{array}{c}\text { Radio- } \\
\text { graphy }\end{array}$ & $\begin{array}{c}\text { Ultra- } \\
\text { sonography }\end{array}$ & Endoscopy \\
\hline Accuracy & - & - & + \\
Invasiveness & + & + & - \\
Abalone safety & + & + & + \\
Operator safety & - & + & + \\
Portability & - & + & + \\
Ease of use & + & + & - \\
Ease of interpretation & + & - & + \\
Speed & - & + & + \\
Cost & - & - & + \\
\hline
\end{tabular}

demonstrated that endoscopy is the method of choice (Table 6). It provided accurate diagnoses in $92 \%$ of the cases (Table 4), whereas X-ray and ultrasound provided accurate diagnoses in 69 and $83 \%$ of the cases respectively (Table 2). Endoscopy, however, is invasive and while there may be sub-lethal effects, apparently this screening procedure does not cause increased mortality (Trial 3).

Acknowledgements. This research was funded with the help of Otago Research Grant 99-739 to J.A.K. We thank Bill Dickson (Portobello Marine Laboratory) for his boating skills, advice and support in the collection of the abalone. We also thank Lesley Schofield (Department of Laboratory Animals, University of Otago), Chris and Daryl (Televid Services, Dunedin) and Alison Cree (Department of Zoology, University of Otago) for the supply of X-ray equipment, ultrasound apparatus and endoscope respectively. Special thanks to Grant Hopkins, Murray Clarke, Amy West, Simon Muncaster and Adelle Heineman for diving the murky Catlins waters to collect the abalone.

\section{LITERATURE CITED}

Aquilina B, Roberts R (2000) A method for inducing muscle relaxation in the abalone, Haliotis iris. Aquaculture 190: 403-408

Clavier J (1992) Infestation of Haliotis tuberculata shells by Cliona celata and Polydora species. In: Shepherd SA, Tegner MJ, Guzmann del Proo SA (eds) Abalone of the world: biology, fisheries and culture. Supplementary papers. Fisheries Research Papers No. 24, Department of Fisheries, Adelaide, South Australia, p 16-20

Davenport J (1993) Ultrasonography: a non-invasive tool for the study of structure and mechanical events in marine animals. J Mar Biol Assoc UK 73:461-464

Friedman CS, Grindley R, Keogh JA (1997) Isolation of a fungus from shell lesions of New Zealand abalone, Haliotis iris Martyn and $H$. australis Gmelin. Mollusc Res 18: 313-324

Grindley RM, Keogh JA, Friedman CS (1998) Shell lesions in New Zealand Haliotis spp. (Mollusca, Gastropoda). J Shellfish Res 17:805-811 
Haefner PA Jr, Sheppard B, Barto J, McNeil E, Cappellino V (1996) Application of ultrasound to molluscan physiology: non-invasive monitoring of cardiac rate in the blue mussel, Mytilus edulis Linnaeus, 1758. J Shellfish Res 15: 685-687

Hahn KO (1989) Biotic and abiotic factors affecting the culture of abalone. In: Hahn KO (ed) Handbook of culture of abalone and other marine gastropods. CRC Press, Boca Raton, FL, p 129-134

Kojima H, Imajima M (1982) Burrowing polychaetes in the shells of abalone Haliotis diversicolor aquatilus chiefly of the species of Polydora. Bull Jpn Soc Sci Fish 48:31-35

Martin-Robichaud DJ, Rommens M (2001) Assessment of sex and evaluation of ovarian maturation of fish using ultrasonography. Aquac Res 32:113-120

Moccia RD, Wilkie EJ, Munkittrick KR, Thompson WD (1984) The use of needle fibre endoscopy in fish for in vivo examination of visceral organs, with special reference to ovarian evaluation. Aquaculture 56: 139-149

Ortenburger AI, Jansen ME, Whyte SK (1996) Nonsurgical videolaparoscopy for determination of reproductive status of the Arctic charr. Can Vet J 37: 96-100

Schofield JC, Grindley RM, Keogh JA (2001) The use of diagnostic radiology to detect shell irregularities in the New

Editorial responsibility: Albert Sparks,

Seattle, Washington, USA
Zealand paua (abalone) Haliotis iris. Lab Anim 35: 167-171

Smith AM, Nelson CS, Spencer HG (1998) Skeletal carbonate mineralogy of New Zealand bryozoans. Mar Geol 151: 27-46

Thomas M, Day RW (1995) Site selection by a small predator: why does the gastropod Haustrum baileyanum drill over muscle tissue of the abalone Haliotis rubra? Mar Freshw Res 46:647-655

Tong LJ, Moss GA, Redfearn P, Illingworth J (1992) A manual of techniques for culturing paua, Haliotis iris, through to the early juvenile stage. New Zealand Fisheries Technical Report 31. Ministry of Agriculture and Fisheries, Wellington Vermeij GJ (1993) Solutions to dissolution. In: Vermeij GJ (ed) A natural history of shells. Princeton University Press, Princeton, $\mathrm{p} 45-48$

Ward JE, Beninger PG, MacDonald BA, Thompson RJ (1993) Suspension-feeding mechanisms in bivalves: resolution of current controversies using endoscopy. J Shellfish Res 12: 157

White HI, Hecht T, Potgieter B (1996) The effect of four anaesthetics on Haliotis midae and their suitability for application in commercial abalone culture. Aquaculture 140: 145-151

Submitted: September 6, 2001; Accepted: April 16, 2002 Proofs received from author(s): July 2, 2002 